\title{
Thymoma: A clinicopathologic study based on the new World Health Organization classification
}

\author{
Kazuo Nakagawa, MD \\ Hisao Asamura, MDa \\ Yoshihiro Matsuno, $\mathrm{MD}^{\mathrm{b}}$ \\ Kenji Suzuki, MDa \\ Haruhiko Kondo, MD \\ Arafumi Maeshima, $\mathrm{MD}^{\mathrm{b}}$ \\ Etsuo Miyaoka, $\mathrm{PhD}^{\mathrm{c}}$ \\ Ryosuke Tsuchiya, $\mathrm{MD}^{\mathrm{a}}$
}

From the Divisions of Thoracic Surgery ${ }^{\mathrm{a}}$ and Pathology, ${ }^{\mathrm{b}}$ National Cancer Center Hospital and Research Institute, Tokyo, Japan; and the Department of Mathematics, ${ }^{c}$ Tokyo University of Science, Tokyo, Japan.

Received for publication Aug 20, 2002; revisions requested Oct 17, 2002; revisions received Oct 29, 2002; accepted for publication March 13, 2003.

Address for reprints: Hisao Asamura, MD, Division of Thoracic Surgery, National Cancer Center Hospital, 1-1, Tsukij 5-chome, Chuo-ku, Tokyo 104-0045, Japan (E-mail: hasamura@ncc.go.jp).

J Thorac Cardiovasc Surg 2003;126: $1134-40$

Copyright () 2003 by The American Association for Thoracic Surgery

$0022-5223 / 2003 \$ 30.00+0$

doi:10.1016/S0022-5223(03)00798-0
Objective: This study explored the relationship between the histologic subtype of thymoma according to the new World Health Organization histologic classification and the clinical findings, as well as the prognostic significance of the classification.

Methods: A total of 130 patients with thymoma, who underwent resection at the National Cancer Center Hospital, Tokyo, from 1962 to 2000, were studied retrospectively. The histologic subtype of thymoma was determined according to the new World Health Organization histologic classification. The stage was also determined according to a modified Masaoka's classification as stage I, II, III, IVa, or IVb. To determine the factors that may affect the prognosis of thymoma, a multivariate analysis with Cox's proportional hazards regression model was performed.

Results: The distribution of histologic subtype was type A ( $\mathrm{n}=18)$, type $\mathrm{AB}(\mathrm{n}=$ $56)$, type $\mathrm{B} 1(\mathrm{n}=15)$, type $\mathrm{B} 2(\mathrm{n}=29)$, and type $\mathrm{B} 3(\mathrm{n}=12)$. A close correlation was seen between the histologic subtype and stage $(P=.000)$. The overall survivals at 5 and 10 years were $92 \%$ and $91 \%$, respectively. The 5- and 10 -year survivals according to stage were $100 \%$ and $100 \%$ (stage I, $\mathrm{n}=40$; stage II, $\mathrm{n}=54$ ), $81 \%$ and $76 \%$ (stage III, $\mathrm{n}=25$ ), and $47 \%$ and $47 \%$ (stage IV, $\mathrm{n}=11$ ), respectively. The difference in survival between stage III and stage IV was significant $(P=.000)$. Patients with type A or AB thymoma demonstrated a $100 \%$ survival at both 5 and 10 years. Recurrences were seen in 12 patients with complete resection. According to a multivariate analysis, tumor size $(P=.001)$, completeness of resection $(P=$ $.002)$, histologic subtype $(P=.011)$, and stage $(P=.00)$ were significant prognostic factors.

Conclusion: The World Health Organization histologic classification significantly correlated with the clinical stage. Tumor size, completeness of resection, histologic subtype, and stage predicted the prognosis of thymoma.

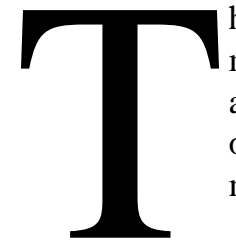

hymomas are neoplasms that arise from epithelial cells of the thymus. ${ }^{1,2}$ Because of their low incidence, wide range of histologic appearance, and unique biologic behavior, they have been a source of controversy for many years. The histologic classification of thymoma in particular is still a topic of dispute. ${ }^{3-6}$

Bernatz and colleagues ${ }^{7}$ classified thymoma into 4 histologic subtypes according to the relative proportion of epithelial cells and lymphocytes: predominantly lymphocytic, mixed, epithelial, and spindle cell. In many studies, no significant correlation was observed between this histologic subtype and clinical behavior, and 
probably the only important prognostic determinant was invasion. ${ }^{8-11}$ In 1985, Marino and Müller-Hermelink ${ }^{12}$ developed a new histologic classification of thymic epithelial neoplasm based on the morphologic and functional resemblance of neoplastic epithelial cells to normal thymic cortical and medullary epithelial cells: medullary, mixed, predominantly cortical, and cortical. In addition, they proposed well-differentiated thymic carcinoma as an organotypic low-grade carcinoma of the thymus. ${ }^{13}$ Some studies showed that this classification was useful for predicting clinical behavior, ${ }^{14-17}$ whereas others disputed its clinical relevance. ${ }^{10,18}$ On the other hand, Moran and Suster ${ }^{19}$ presented 3 categories of thymic epithelial tumor based simply on the grade of histologic atypia: thymoma, atypical thymoma, and thymic carcinoma. Thus, several histologic classifications for thymoma have been published, but the prognostic significance of such histologic classification is still controversial. Recently, the World Health Organization (WHO) histologic typing of tumors of the thymus was published. ${ }^{20}$ Only a few studies have been performed to evaluate the clinical and prognostic relevance of this histologic classification. ${ }^{21-23}$

In this study, we retrospectively reviewed surgically resected thymomas on the basis of the WHO histologic classification and evaluated the classification's clinical and prognostic usefulness. We also performed a multivariate analysis to determine which factors independently predicted the prognoses of patients with thymoma.

\section{Materials and Methods \\ Patients}

In the 38-year period from 1962 to 2000, there were 152 patients with thymoma at the National Cancer Center Hospital, Tokyo. Eight patients who were treated initially elsewhere and 14 patients for whom an adequate tissue specimen was not available for pathologic review were excluded from the present study. Therefore, a total of 130 patients with thymoma were considered for review. Their pathologic and clinical features were studied retrospectively. The medical records were extensively reviewed in terms of clinicopathologic issues, including allied disease, type of operation, perioperative therapy, mode of recurrence, and prognosis. Total thymectomy was defined as the resection of the entire thymus and mediastinal fatty tissue between both phrenic nerves; thymomectomy was defined as the resection of thymoma leaving only residual thymic tissue behind; complete resection was defined as no macroscopic or microscopic residual tumor; and incomplete resection was defined as evident macroscopic or microscopic residual tumor. Recurrence was defined as any evidence of tumor, such as regrowth of tumor in the mediastinum, pleural dissemination, or pulmonary metastasis, detected by imaging or pathologic examination during follow-up.

\section{Pathology}

In each case, 2 investigators (K.N. and Y.M.) reviewed the hematoxylin-eosin-stained formalin-fixed paraffin sections of surgically resected thymoma specimens in our pathology file. The histologic subtype of thymoma was further determined according to the WHO classification ${ }^{20}$ as follows. Type A: a tumor composed of a population of spindle or oval neoplastic thymic epithelial cells lacking nuclear atypia and accompanied by few or non-neoplastic lymphocytes. Type AB: a tumor in which foci with the features of type A thymoma are admixed with foci rich in lymphocytes. Type B1: a tumor that resembles the normal functional thymus in that it combines large expanses with an appearance practically indistinguishable from normal thymic cortex with areas resembling thymic medulla. Type B2: a tumor in which the neoplastic epithelial component appears as scattered plump cells with vesicular nuclei and distinct nucleoli among a heavy population of lymphocytes, perivascular spaces are common and sometimes very prominent, and a perivascular arrangement of tumor cells resulting in a palisading effect may be seen. Type B3: a type of thymoma predominantly composed of round or polygonal epithelial cells exhibiting no or mild atypia admixed with a minor component of lymphocytes, resulting in a sheet-like growth of the neoplastic epithelial cells. We also performed a careful histologic assessment to determine whether the tumor invaded the capsule.

\section{Clinical Stage}

A modified Masaoka's classification ${ }^{24,25}$ was used for the clinical staging of patients with thymoma, in which thymic tumors that infiltrate into but not through the capsule still belong to stage I. This staging system was identical to the WHO staging guidelines ${ }^{20}$ and can be summarized as follows. Stage I: encapsulated, a thymoma completely surrounded by a fibrous capsule of varying thickness that is not infiltrated by tumor growth (thymic tumors that infiltrate into but not through the capsule still belong in this category). Stage II: minimally invasive, a thymoma surrounded by a capsule that is focally infiltrated by tumor growth or that invades the mediastinal fat (the capsular invasion needs to be complete for the tumor to be placed in this category). Stage III: widely invasive, a thymoma spreading by direct extension into adjacent structures such as pericardium, large vessels, or lung. Stage IVa: with implants, a thymoma in which tumor nodules separate from the main mass are found on the pericardial or pleural surface. Stage IVb: with lymph node or distant metastases, a thymoma that involves 1 or more lymph nodes anatomically separate from the main mass or that was accompanied by embolic metastases to distant site.

\section{Statistical Analyses}

To compare frequencies among different groups, a $\chi^{2}$ test or Tukey's significant difference test was used. Survival was measured from the day of the operation until death or the last follow-up visit. The Kaplan-Meier method was used to estimate time to death from thymoma-related causes and a 95\% confidence interval. Death resulting from worsening of myasthenia gravis (MG) was considered thymoma-related. All deaths that were not related to the tumor (thymoma) were excluded from the calculation of survival curves. Deaths resulting from other causes were considered as censored. Differences in survival were tested by the log-rank test. To identify the factors that may affect the prognosis, a multivariate analysis using Cox's proportional hazards regression model was performed. The present multivariate analysis included 7 variables: 
TABLE 1. The clinical profiles of treatment

\begin{tabular}{lc}
\hline Profiles & No of patients $(\%)$ \\
\hline Type of operation & (Total No. $=130)$ \\
Total thymectomy & $71(55)$ \\
Thymomectomy & $55(42)$ \\
Exploratory thoracotomy & $4(3)$ \\
Completeness of resection & (Total No. $=130)$ \\
Complete & $124(95)$ \\
Incomplete & $6(5)$ \\
Perioperative therapy & $11(8)^{*}$ \\
Preoperative & $4(3)$ \\
Radiation therapy & 0 \\
Chemotherapy & 4 \\
Postoperative & $7(5)$ \\
Radiation therapy & 6 \\
Chemotherapy & 1 \\
\hline
\end{tabular}

${ }^{*}$ One patient had both preoperative and postoperative therapies.

gender, age, presence of MG, completeness of resection, tumor size, tumor stage, and histologic subtype. These analyses were performed with SPSS version 11.0 statistical software (SPSS, Inc, Chicago, Ill).

\section{Results}

\section{Clinical Findings}

There were 54 men and 76 women (male to female ratio, 0.72 ) who ranged in age from 15 to 83 years (mean age, $54 \pm 13$ years). Sixteen patients (12\%) had MG, occurring preoperatively and postoperatively in 8 patients each. None of the patients had allied diseases other than MG. Forty patients $(31 \%)$ were in stage I, 54 patients $(42 \%)$ were in stage II, 25 patients $(19 \%)$ were in stage III, 10 patients (7\%) were in stage IVa, and 1 patient (1\%) was in stage IVb. The clinical profiles of 130 patients are summarized in Table 1. A total of 124 patients (95\%) underwent complete resection. In contrast, complete resection was impossible for 6 patients (5\%) because of extensive invasion to the neighboring organs in 2 patients and multiple implants in the thorax in 4 patients. Ten patients $(8 \%)$ received perioperative therapy: preoperatively in 3 patients, postoperatively in 6 patients, and both preoperatively and postoperatively in 1 patient. Four patients were treated with preoperative chemotherapy. The preoperative chemotherapeutic regimens were as follows: cisplatin $25 \mathrm{mg} / \mathrm{m}^{2}$, vincristine $1 \mathrm{mg} / \mathrm{m}^{2}$, doxorubicin $40 \mathrm{mg} / \mathrm{m}^{2}$, and etoposide $80 \mathrm{mg} / \mathrm{m}^{2}$ for 2 cycles (2 patients); cisplatin $60 \mathrm{mg} / \mathrm{m}^{2}$, cyclophosphamide 800 $\mathrm{mg} / \mathrm{m}^{2}$, doxorubicin $45 \mathrm{mg} / \mathrm{m}^{2}$, and etoposide $80 \mathrm{mg} / \mathrm{m}^{2}$ for 2 cycles (1 patient); and cisplatin $80 \mathrm{mg} / \mathrm{m}^{2}$ and etoposide $60 \mathrm{mg} / \mathrm{m}^{2}$ for 2 cycles (1 patient). For postoperative therapy, 6 patients received radiotherapy at 40 to 50 Gy (1 patient in stage II, 4 patients in stage III, and 1 patient in stage IVa), and 1 patient received chemotherapy. The percentage of patients who received postoperative radiotherapy was $1.8 \%(1 / 54)$ in stage II, $16 \%(4 / 25)$ in stage III, and $10 \%(1 / 10)$ in stage IVa.
TABLE 2. The relation between histologic subtype and stage

\begin{tabular}{|c|c|c|c|c|c|c|}
\hline \multirow{2}{*}{$\begin{array}{l}\text { Histologic } \\
\text { subtype }\end{array}$} & \multirow{2}{*}{$\begin{array}{c}\text { No of } \\
\text { patients }\end{array}$} & \multicolumn{5}{|c|}{ Stage } \\
\hline & & I & II & III & IVa & IVb \\
\hline$A$ & 18 & 8 & 7 & 2 & & 1 \\
\hline$A B$ & 56 & 28 & 22 & 6 & & \\
\hline B1 & 15 & 2 & 9 & 4 & & \\
\hline B2 & 29 & 2 & 14 & 6 & 7 & \\
\hline B3 & 12 & & 2 & 7 & 3 & \\
\hline Total & 130 & 40 & 54 & 25 & 10 & 1 \\
\hline
\end{tabular}

TABLE 3. The clinical features of each histologic subtype

\begin{tabular}{|c|c|c|c|c|c|c|}
\hline \multirow{2}{*}{$\begin{array}{l}\text { Histologic } \\
\text { subtype }\end{array}$} & \multirow{2}{*}{$\begin{array}{l}\text { Sex } \\
(M / F)\end{array}$} & \multicolumn{2}{|c|}{ Age (y) } & \multirow{2}{*}{$\begin{array}{l}\text { MG } \\
(\%)\end{array}$} & \multicolumn{2}{|c|}{ Size $(\mathrm{cm})$} \\
\hline & & Mean \pm SD & Range & & Mean \pm SD & Range \\
\hline$A$ & $8 / 10$ & $60 \pm 16$ & $23-83$ & $1(5)$ & $7.9 \pm 3.7$ & $2.0-12.5$ \\
\hline$A B$ & $21 / 35$ & $55 \pm 11$ & $33-83$ & $4(6)$ & $6.9 \pm 2.7$ & $1.2-17$ \\
\hline B1 & $4 / 11$ & $56 \pm 13$ & $35-72$ & $1(7)$ & $6.9 \pm 2.8$ & $3.5-15$ \\
\hline B2 & $14 / 15$ & $49 \pm 12$ & $26-66$ & $7(24)$ & $6.6 \pm 2.5$ & $1.5-11$ \\
\hline B3 & $7 / 5$ & $49 \pm 17$ & $15-79$ & $3(25)$ & $11.5 \pm 7.3^{*}$ & $4.0-28$ \\
\hline Total & $54 / 76$ & $54 \pm 13$ & $15-83$ & $16(12)$ & $7.4 \pm 3.7$ & $1.2-28$ \\
\hline
\end{tabular}

$M G$, Myasthenia gravis.

${ }^{*} P<.05$.

\section{Histologic Findings}

With regard to histologic subtype, type A was found in 18 patients (14\%), type AB in 56 (43\%), type B1 in $15(12 \%)$, type B2 in $29(22 \%)$, and type B3 in $12(9 \%)$. The relationship between tumor stage and histologic subtype is summarized in Table 2. The proportion of tumors in an advanced stage gradually increased from type A to type B3. There was a striking correlation between stage and histologic subtype $\left(\chi^{2}\right.$ test, $\left.P=.000\right)$. One patient with type A thymoma had pulmonary metastases before the operation. The clinical features of each histologic subtype are presented in Table 3. The frequency of association with MG tended to be higher in patients with type B2 or B3 tumor than in those with other histologic subtypes, although this difference was not statistically significant. Despite the subtype as type A, 1 patient had MG. Patients with type B3 thymoma had significantly larger tumors than those with other histologic subtypes (Tukey's significant difference test, $P<.05$ ).

\section{Prognosis}

The overall survivals at 5 and 10 years were $92 \%$ and $91 \%$, respectively. Survival according to the completeness of resection is shown in Figure 1. Patients who underwent complete resection $(n=124)$ had significantly better survival than those with incomplete resection $(\mathrm{n}=6, \log$-rank test, $P=.000$ ). However, there was no difference in survival between patients undergoing total thymectomy and 


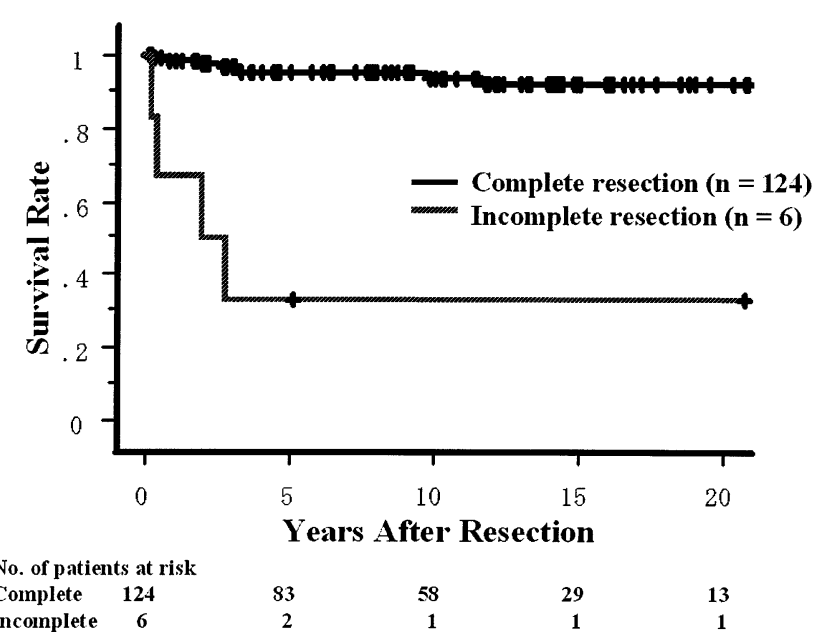

Figure 1. Survival according to the completeness of resection. The 5 - and 10 -year survivals were $96 \%$ and $94 \%$ in patients with complete resection and $33 \%$ and $33 \%$ in patients with incomplete resection, respectively. The difference in survival between the 2 groups is significant $(P=.000)$.

those undergoing thymomectomy. Survival according to tumor size is shown in Figure 2. Patients with a tumor less than $10 \mathrm{~cm}$ in diameter $(\mathrm{n}=108)$ had significantly better survival than those with a tumor $10 \mathrm{~cm}$ or larger $(\mathrm{n}=22$, log-rank test, $P=.000$ ). The survival curves according to histologic subtype are shown in Figure 3. The 5- and 10year survivals according to the histologic subtype were $100 \%$ and $100 \%$ (type $\mathrm{A}$ and $\mathrm{AB}$ ), $100 \%$ and $86 \%$ (type B1), $85 \%$ and $85 \%$ (type B2), and $51 \%$ and $38 \%$ (type B3), respectively. Because there were no thymoma-related deaths among patients with type $\mathrm{A}$ and $\mathrm{AB}$ thymomas, the difference in survival between type $A$ and other histologic subtypes, as well as between type $\mathrm{AB}$ and other histologic subtypes, could not be tested. The differences in survival between type B1 and B 3 as well as between B2 and B3 were significant (log-rank test, $P=.000$ ). The survival curves according to the clinical stage are shown in Figure 4. The 5and 10-year survivals according to stage were $100 \%$ and $100 \%$ (stage I and II), $81 \%$ and $76 \%$ (stage III), and $47 \%$ and $47 \%$ (stage IV), respectively. Because there were no thymoma-related deaths among patients with stage I or stage II thymoma, the difference in survival between stage I and other stages, as well as between stage II and other stages, could not be tested. The difference in survival between stage III and stage IV was significant (log-rank test, $P=.000)$. The presence of MG marginally affected the survival. The 5-year survivals for patients with MG and those without MG were $94 \%$ and $80 \%$, respectively. The difference was marginally significant $(P=.0074)$.

Of 124 patients with complete resection, 12 (9.6\%) experienced a recurrence. The details of patients with recur-

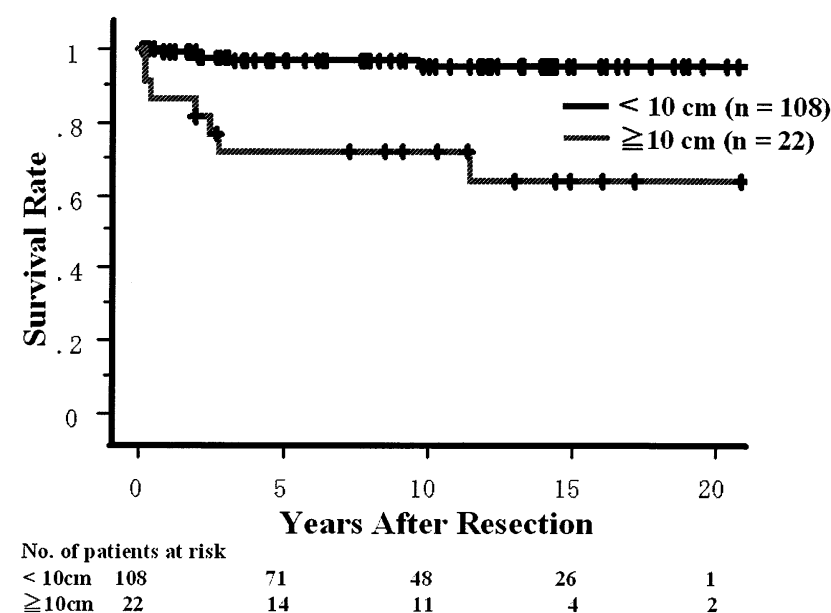

Figure 2. Survival according to tumor size. The 5- and $\mathbf{1 0}$-year survivals were $\mathbf{9 7 \%}$ and $\mathbf{9 5 \%}$ in patients with a tumor less than $\mathbf{1 0}$ cm in diameter and $72 \%$ and $72 \%$ in patients with a tumor $10 \mathrm{~cm}$ or larger, respectively. The difference in survival between the 2 groups is significant $(P=.000)$.

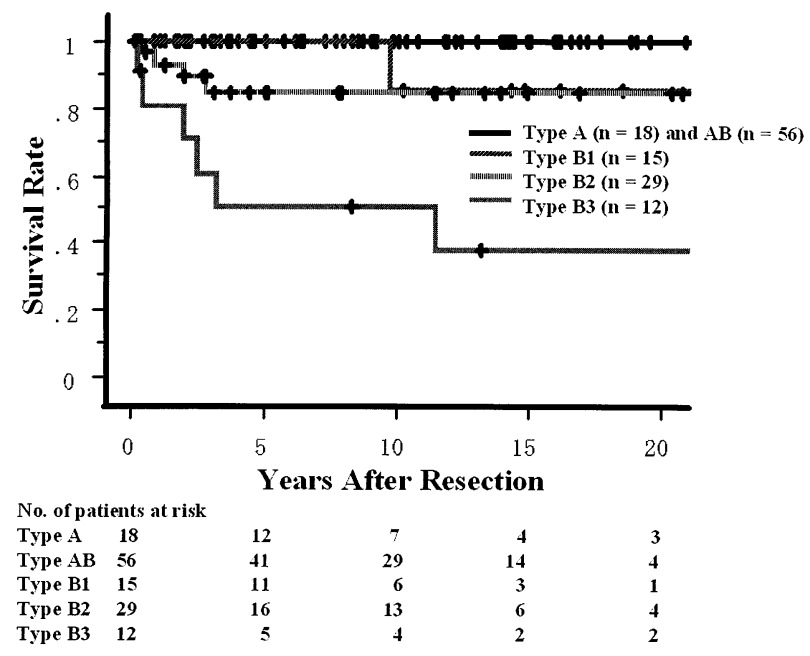

Figure 3. Survival according to the histologic subtype. The 5- and $\mathbf{1 0}$-year survivals according to the histologic subtype were $\mathbf{1 0 0} \%$ and $\mathbf{1 0 0 \%}$ (type $A$ and $A B$ ), $100 \%$ and $86 \%$ (type B1), $85 \%$ and $85 \%$ (type B2), and $51 \%$ and $38 \%$ (type B3), respectively. The difference in survival between type $B 2$ and type $B 3$ is significant $(P=.000)$.

rence are shown in Table 4 . There were 2 local recurrences, 3 distant metastases, 6 pleural disseminations, and 1 recurrence at an unknown site. Three of 18 patients (17\%) with type A thymoma had a recurrence. Two patients had pulmonary metastasis, and 1 patient had local recurrence. One of 56 patients (1.8\%) with type AB thymoma had a pulmonary metastasis. One of 15 patients (6.6\%) with type B1 thymomas had pleural dissemination. Two of 29 patients (7\%) with type B2 thymoma had recurrence (1 local recur- 


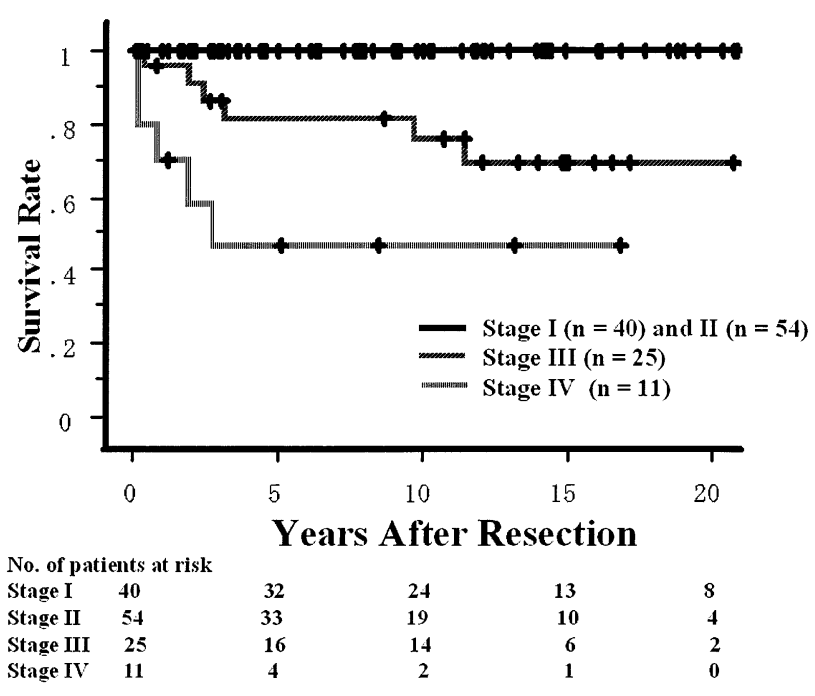

Figure 4. Survival according to the tumor stage. The 5- and 10 -year survivals according to stage were $100 \%$ and $100 \%$ (stages I and II), $81 \%$ and $76 \%$ (stage III), and $47 \%$ and $47 \%$ (stage IV), respectively. The difference in survival between stage III and stage IV is significant $(P=.000)$.

rence and 1 pleural dissemination). Five of 12 patients (42\%) with type B3 thymoma had recurrence (4 pleural dissemination and 1 at an unknown site). According to tumor stage, 1 of 40 patients $(2.5 \%)$ with stage I thymoma and 1 of 54 patients (1.8\%) with stage II thymoma had local recurrence. The former patient had a cervical tumor, which was initially believed to be a thyroid tumor, so he only underwent tumor resection. However, the pathologic diagnosis of the resected specimen was thymoma. Although there was no macroscopic or microscopic residual tumor, the resection in this case may have been incomplete. Seven of 25 patients (28\%) with stage III thymoma had recurrence (6 pleural dissemination and 1 at an unknown site).

During the follow-up period, 33 deaths occurred. Eleven patients $(33 \%)$ died of thymoma-related causes. The remaining 22 patients died of other causes ( 7 of other malignancies, 5 of pneumonia, 4 of heart diseases, 2 of brain diseases, 1 of renal failure, 1 of sepsis, and 2 of unknown causes). None of the patients with stage I or II thymomas or with type $\mathrm{A}$ or $\mathrm{AB}$ thymoma died of thymoma-related causes.

\section{Multivariate Analyses}

Because of the striking correlation between stage and histologic subtype, these 2 variables were each entered into multivariate analyses together with 5 other variables (gender, age, presence of MG, completeness of resection, and tumor size). Therefore, 2 separate multivariate analyses were performed with different combinations of 6 variables. The results of each analysis are shown in Tables 5 and 6.
Tumor size $(P=.001)$, completeness of resection $(P=$ $.002)$, histologic subtype $(P=.011)$, and stage $(P=.00)$ were noted as significant prognostic factors.

\section{Discussion}

The WHO histologic typing of tumors of the thymus was first published in $1999 .{ }^{20} \mathrm{~A}$ few clinicopathologic studies have examined the usefulness of this classification. ${ }^{21-23}$ Among these reports, only one, by Okumura and colleagues, ${ }^{23}$ evaluated the clinical and prognostic significance of this classification, and they concluded that the histologic subtype based on the WHO classification reflected the oncologic behavior of thymoma.

In this study, the histologic subtype based on the WHO histologic classification could be determined in all 130 thymomas. Twelve of these were considered type B3 thymoma. Type B3 thymoma is defined as a thymoma predominantly composed of epithelial cells with no or mild atypia. In our series, several thymomas were actually composed of more than 1 histologic subtype including B3. The WHO classification does not clearly define how to deal with cases involving type B3 thymomas. Kirchner and colleagues ${ }^{26}$ reported that a diagnosis of well-differentiated thymic carcinoma can be made only in cases in which more than 50\% of the tumor shows this typical morphology. On the other hand, Quintanilla-Martinez and coworkers ${ }^{15,16}$ suggested that tumors with any area in which this diagnostic histology could be recognized should be classified as well-differentiated thymic carcinoma. In the present study, we adopted the latter criteria and included 3 such cases in type B3. These 3 cases followed aggressive clinical courses; therefore, the diagnostic criteria described by Quintanilla-Martinez and coworkers seem appropriate. The diagnostic criteria for type B3 should be further refined and standardized.

Regarding the correlation between histologic subtype and clinical findings of thymoma, the frequency of association with MG tended to be higher in patients with type B2 or B3 tumor than in those with other histologic subtypes, although this difference was not significant. We also found that the histologic subtype based on the WHO classification was closely related to the tumor stage. The proportion of tumors in an advanced stage gradually increased from type A to type B3. In regard to the prognosis of each histologic subtype, patients with type $\mathrm{A}$ and $\mathrm{AB}$ thymoma had good prognoses, with no thymoma-related deaths. In contrast, the prognoses of patients with type B thymoma tended to gradually worsen from B1 to B3. From a clinicopathologic viewpoint, the WHO histologic classification seems to have clinical and prognostic value. The relationship between histologic subtype and sensitivity to chemotherapy and radiotherapy could not be clearly determined in this study. Further investigation is necessary. 
TABLE 4. Clinicopathologic features of patients who had tumor recurrence after complete resection

\begin{tabular}{|c|c|c|c|c|c|c|}
\hline $\begin{array}{l}\text { Patient No. } \\
\text { (sex, age) }\end{array}$ & $\begin{array}{l}\text { Histologic } \\
\text { subtype }\end{array}$ & Stage & Recurrence & $\begin{array}{l}\text { Interval to recurrence } \\
\text { from operation }\end{array}$ & $\begin{array}{l}\text { Treatment for } \\
\text { recurrent tumors }\end{array}$ & Outcome \\
\hline $\begin{array}{c}1 \\
(F, 36) \\
2\end{array}$ & A & 1 & Local & 16 y 8 mo & Resection & Alive at $15 \mathrm{y}$ \\
\hline $\begin{array}{c}(\mathrm{M}, 59) \\
3\end{array}$ & A & 1 & PM & $3 y$ & Resection and CT & Alive at $6 \mathrm{y}$ \\
\hline $\begin{array}{l}(F, 58) \\
\quad 4\end{array}$ & $A B$ & II & PM & $3 y$ & Resection & Alive at $15 \mathrm{y}$ \\
\hline $\begin{array}{c}(F, 28) \\
5\end{array}$ & B2 & II & Local & $6 y$ & Resection and RT & Alive at $5 \mathrm{y}$ \\
\hline $\begin{array}{c}(F, 55) \\
6\end{array}$ & B1 & III & PD & $6 y$ & Resection & DOT at $4 \mathrm{y}$ \\
\hline $\begin{array}{c}(\mathrm{M}, 64) \\
7\end{array}$ & B2 & III & PD & $6 y$ & Resection & Alive at $5 \mathrm{y}$ \\
\hline $\begin{array}{l}(\mathrm{F}, 43) \\
8\end{array}$ & B3 & III & PD & 18 y & Resection & Alive at $12 \mathrm{y}$ \\
\hline $\begin{array}{c}(F, 65) \\
9\end{array}$ & B3 & III & PD & 1 y 5 mo & CT & DOT at $5 \mathrm{mo}$ \\
\hline $\begin{array}{c}(F, 42) \\
10\end{array}$ & B3 & III & PD & $6 \mathrm{mo}$ & CT & DOT at $11 \mathrm{mo}$ \\
\hline $\begin{array}{c}(F, 60) \\
11\end{array}$ & B3 & III & PD & $4 \mathrm{mo}$ & CT & DOT AT 2 y \\
\hline $\begin{array}{c}(\mathrm{M}, 15) \\
12\end{array}$ & B3 & III & Unknown & Unknown & Unknown & $\mathrm{DOT}$ at $11 \mathrm{y}$ \\
\hline$(\mathrm{M}, 65)$ & A & $\mathrm{IVb}$ & PM & $2 y$ & CT & Alive at $6 \mathrm{y}$ \\
\hline
\end{tabular}

$P M$, Pulmonary metastasis; $P D$, pleural dissemination; $C T$, chemotherapy; $R T$, radiation therapy; $D O T$, died of thymoma-related causes.

Several studies have shown that medullary and mixed thymomas according to the Müller-Hermelink classification, which are probably included in the type $\mathrm{A}$ and $\mathrm{AB}$ histologic subtypes in the WHO classification, have a good prognosis, ${ }^{12,17,18}$ and 1 author concluded that these kinds of thymoma were benign tumors. ${ }^{16}$ On the other hand, Shimosato and Mukai ${ }^{2}$ and Pan and colleagues ${ }^{21}$ indicated that it was dangerous to consider these tumors as benign. In fact, in our series, 2 type $\mathrm{A}$ thymomas and 1 type $\mathrm{AB}$ thymoma had pulmonary metastases. Although most type $A$ and $A B$ thymomas follow a benign clinical course, they are not absolutely benign tumors.

Although factors such as completeness of resection, tumor size, stage, and histology have been mentioned as prognostic factors in thymoma, $8,9,16-18,27-30$ the presence or absence of tumor invasion has been uniformly recognized as a prognostic factor. ${ }^{3,19}$ According to the present multivariate analyses, the histologic subtype by the WHO classification and tumor size should be recognized as factors that may strongly affect the prognosis. Indeed, although staging according to Masaoka's classification ${ }^{24}$ reflected the prognosis, several important revisions of this staging system have been strongly recommended. ${ }^{3,10,19}$ The definitions of stages I and II, in which stage I is defined as a thymoma without capsular invasion and stage II is defined as a thymoma with capsular invasion, especially need to be revised. Our present study demonstrated that there was no significant difference
TABLE 5. Multivariate analysis (stage excluded)

\begin{tabular}{lcc}
\hline Variables & Risk ratio & $\boldsymbol{P}$ value \\
\hline Histologic subtype & 2.89 & .011 \\
Complete resection & 9.5 & .002 \\
Tumor size & 1.26 & .001 \\
\hline
\end{tabular}

TABLE 6. Multivariate analysis (histologic subtype excluded)

\begin{tabular}{lcc}
\hline Variables & Risk ratio & $\boldsymbol{P}$ value \\
\hline Stage & 5.08 & .00 \\
Tumor size & 1.252 & .01 \\
\hline
\end{tabular}

in survival between stages I and II, with 5-year and 10-year survival of $100 \%$, respectively. Similar results have been observed in several other studies. ${ }^{14,17,23,29}$ These results clearly show that capsular invasion in thymoma has no prognostic significance, and therefore capsular invasion in thymoma should not be used in the staging system for thymoma. The present stage I and stage II should be merged and reclassified as stage I. Subsequently, the heterogeneous stage III should be further divided into stage II and stage III.

This retrospective study clearly demonstrated that the prognoses of patients were also affected by the histologic 
subtype of thymoma, and it was not the simple matter of tumor progression according to stage. Therefore, in determining the therapeutic strategy of patients with thymoma, the histologic subtype along with stage should be always considered, although the uniform staging system should be applied in any type of thymic epithelial tumors. The staging system also should be further refined according to these findings.

We are grateful to Dr Yukio Simosato, Visiting Professor, Department of Pathology, Keio University School of Medicine, for his advice on histologic interpretation of cases.

\section{References}

1. Rosai J, Levine GD. Tumors of the Thymus. In: Harlan I, Ferminger MD, editors. Atlas of tumor pathology, 2nd series, fascicle 13. Washington (DC): The Armed Forces Institute of Pathology; 1976. p. 1-221.

2. Shimosato Y, Mukai K. Tumors of the Mediastinum. In: Rosai J, Sobin LH, editors. Atlas of tumor pathology, 3rd series, fascicle 21. Washington (DC): The Armed Forces Institute of Pathology; 1997. p. 40-120.

3. Shimosato Y. Controversies surrounding the subclassification of thymoma. Cancer. 1994;74:542-4.

4. Harris NL, Müller-Hermelink HK. Thymoma classification. A siren's song of simplicity. Am J Clin Pathol. 1999;112:299-303.

5. Kornstein MJ. Thymoma classification: my opinion. Am J Clin Pathol. 1999;112:304-7.

6. Suster S, Moran CA. Thymoma classification. The ride of the Valkyries? Am J Clin Pathol. 1999;112:308-10.

7. Bernatz PE, Harrison EG, Clagett OT. Thymoma: a clinicopathologic study. J Thorac Cardiovasc Surg. 1961;42:424-44.

8. Maggi G, Giaccone G, Donadio M, Ciuffreda L, Dalesio O, Leria G, et al. A review of 169 cases, with particular reference to results of surgical treatment. Cancer. 1986;58:765-76.

9. Lewis JE, Wick MR, Scheithauer BW, Bernatz PE, Taylor WF. Thymoma. A clinicopathologic review. Cancer. 1987;60:2727-43.

10. Kornstein MJ, Curran WJ Jr, Turrisi AT 3rd, Brooks JJ. Cortical versus medullary thymomas: a useful morphologic distinction? Hum Pathol. 1988;19:1335-9.

11. Wick MR. Assessing the prognosis of thymomas. Ann Thorac Surg. 1990;50:521-2.

12. Marino M, Müller-Hermelink HK. Thymoma and thymic carcinoma. Virchows Arch A Pathol Anat Histopathol. 1985;407:119-49.

13. Kirchner T, Müller-Hermelink HK. New approaches to the diagnosis of thymic epithelial tumors. Prog Surg Pathol. 1989;10:167-89.

14. Pescarmona E, Rendima EA, Venuta F. Analysis of prognostic factors and clinicopathological staging of thymomas. Ann Thorac Surg. 1990; 50:534-8.
15. Quintanilla-Martinez L, Wilkins EW, Ferry JA, Harris NL. Thymomamorphologic subclassification correlates with invasiveness and immunohistologic features: a study of 122 cases. Hum Pathol. 1993;24:95869.

16. Quintanilla-Martinez L, Wilkins EW Jr, Choi N, Efird J, Hug E, Harris NL. Thymoma. Histologic subclassification is an independent prognostic factor. Cancer. 1994;74:606-17.

17. Lardinois D, Rechsteiner R. Prognostic relevance of Masaoka and Müller-Hermelink classification in patients with thymic tumors. Ann Thorac Surg. 2000;69:1550-5.

18. Pan CC, Wu HP, Yang CF, Chen WY, Chiang H. The clinicopathological correlation of epithelial subtyping in thymoma: a study of 112 consecutive cases. Hum Pathol. 1994;25:893-9.

19. Moran CA, Suster S. Thymoma atypical thymoma, and thymic carcinoma. A novel conceptual approach to the classification of thymic epithelial neoplasms. Am J Clin Pathol. 1999;111:826-33.

20. Rosai J. Histological typing of tumors of the thymus. World Health Organization International Histological Classification of Tumors. 2nd ed. New York, Berlin: Springer-Verlag; 1999.

21. Pan CC, Chen WY, Chiang H. Spindle cell and mixed spindle/lymphocytic thymomas: an integrated clinicopathologic and immunohistochemical study of 81 cases. Am J Surg Pathol. 2001;25:111-20.

22. Okumura M, Miyoshi S, Fujii Y, Takeuchi Y, Shiono H, Inoue M, et al. Clinical and functional significance of WHO classification on human thymic epithelial neoplasms: a study of 146 consecutive tumors. Am J Surg Pathol. 2001;25:103-10.

23. Okumura M, Ohta M, Tateyama H, Nakagawa K, Matsumura A, Maeda H, et al. The WHO Health Organization histologic classification system reflects the oncologic behavior of thymoma. Cancer. 2002;94:624-32.

24. Masaoka A, Monden Y, Nakahara K, Tanioka T. Follow-up study of thymomas with special reference to their clinical stages. Cancer. 1981;48:2485-92.

25. Koga K, Matsuno Y, Noguchi M, Shimosato Y. A review of 79 thymomas. Pathol Int. 1994;44:359-67.

26. Kirchner T, Schalke B, Buchwald J, Ritter M, Marx A, MüllerHermelink HK. Well-differentiated thymic carcinoma: an organotypical low-grade carcinoma with relationship to cortical thymoma. Am J Surg Pathol. 1992;16:1153-69.

27. Maggi G, Casadio C, Cavallo A, Cianci R, Molinatti M, Ruffini E. Thymoma: results of 241 operated cases. Ann Thorac Surg. 1991;51: $152-6$.

28. Blumberg D, Port JL, Weksler B, Delgado R, Rosai J, Bains MS, et al. Thymoma: a multivariate analysis of factors predicting survival. Ann Thorac Surg. 1995;60:908-13.

29. Regnard J-F, Magdeleinat P, Dromer C. Prognostic factors and longterm results after thymoma resection: a series of 307 patients. $J$ Thorac Cardiovasc Surg. 1996;112:376-84.

30. Wilkins KB, Sheikh E, Green R, Patel M, George S, Takano M, et al. Clinical and pathologic predictors of survival in patients with thymoma. Ann Surg. 1999;230:562-72. 